\title{
The Country of Origin Effect for Brazilian Fresh Fruits: A Study Using Partial Least Squares Procedures
}

\author{
Janaina de Moura Engracia Giraldi (Corresponding author) \\ Tenured Professor at FEA-RP \\ University of São Paulo (USP), Brazil \\ Av. Bandeirantes, 3900. Ribeirão Preto (SP), Brazil. CEP: 14.040-900 \\ Tel: 55-(16)-3602-4970Ｅ-mail: jgiraldi@usp.br
}

\author{
Isadora Bacha Lopes \\ Master of Science in Business Administration by the University of São Paulo, Brazil \\ Av. Bandeirantes, 3900. Ribeirão Preto (SP), Brazil. CEP: 14.040-900 \\ Tel: 55-(16)-3602-4970Ｅ-mail: isadora_lopes@yahoo.com
}

Received: July 13, $2012 \quad$ Accepted: July 24, $2012 \quad$ Published: October 1, 2012

doi:10.5296/jmr.v4i4.2102 URL: http://dx.doi.org/10.5296/jmr.v4i4.2102

This research has received financial support from FAPESP/Brazil

\begin{abstract}
The image of a product or brand refers to the set of associations related to this product or brand, which is stored in the consumer's memory, and it directly affects the evaluation of products made in this country, leading to what is called "country of origin effect" ("COO effect"). In spite of this subject's importance, Brazilian studies on the effects related to COO information are still in their first steps. This study intended to investigate the COO effect in the consumer's evaluation process of buying alternatives, considering Brazilian fresh fruits. The problem investigated was: What is the impact of Brazil's image in the evaluation of this country's fresh fruits? A quantitative, descriptive study was carried out. The empirical research has used an indirect approach to measure the $\mathrm{COO}$ effect, which has not been seen before in past researches: a structural equation modeling approach. The resulting dimensions of Brazil's image found were Product Evaluation, Brazil's Respect and Importance, Art Evaluation, Affection toward Brazil and Communication and Distribution Evaluation. In conclusion, it was seen that the
\end{abstract}


COO effect exists for Brazilian fresh fruits and it is positive, meaning that the image respondents have about Brazil positively affects their attitudes toward such product.

Keywords: Country image, Country of origin effect, Brazil, fresh fruits, PLS. 


\section{Introduction}

The image of a product or brand refers to the set of associations related to this product or brand, which is stored in the consumer's memory. A positive image is associated to the consumer's loyalty to the product or brand, his or her positive beliefs about their attributes and his or her disposition to look for the product or brand on stores. Consumers have mental images of products, as well as images of different countries, including product suppliers and touristic destinations, among other possibilities. In an analogy, it can be said that the image of a country is the set of associations that exist between the country and other information, which is stored in the consumer's memory.

As for Roth and Diamantopoulos (2009) and Laroche et al. (2005), the existing literature about "country image" did not reach a consensus on how to conceptualize and operationalize this construct, as explained below. A common fact in different concepts of country image is the consideration of this concept's multidimensionality, referring not only to product-related aspects but to other elements. The images consumers form about a country are based on the inferences performed from both marketing and ambient stimuli, as well as the people's perception of the country's population, economic development and quality of products made in this country (Jaffe and Nebenzahl, 2001).

Still according to Jaffe and Nebenzahl (2001), the image of a country affects its product's evaluation. In turn, the experience with products leads to changes in country image. The image of a country directly affects the evaluation of products made in this country, leading to what is called "country of origin effect" (COO effect), which is the object of this study.

The COO effect has received many definitions in the literature, referring generally to the influence of information about a country on the attitudes and behaviour toward a product or brand. This issue is especially important due to the growth of the international market and to the advent of new production technologies. Marketing professionals can take advantage of $\mathrm{COO}$ effect, using its positive biases or neutralizing negative ones over consumers' perception during their buying process' decision taking.

In spite of this subject's importance, Brazilian studies on the effects related to COO information are still in their first steps, stressing the importance of this study. The Brazilian investigations on this issue are characterized by a strong descriptive component, aiming to detect the existence of COO effects, among other objectives (Ayrosa, 2000). As most of the literature on this subject refers to non-Brazilian products, the present study intended to investigate the $\mathrm{COO}$ effect in the consumer's evaluation process of buying alternatives, considering Brazilian products sold abroad.

Brazil is one of the world leaders in both production and exportation of several agricultural and livestock products, being the third world-pole of fruit culture. In this context, the general problem to be investigated in the present study is: What is the impact of Brazil's image in the evaluation of this country's fresh fruits? In order to do so, a quantitative, descriptive study was carried out on the effects of Brazil's image over the foreign consumers' evaluation of Brazilian fresh fruits. The study design adopted was a simple transversal, descriptive research. The empirical research has used an indirect approach to measure the $\mathrm{COO}$ effect, which has not 
been seen before in past researches: a structural equation modeling approach. This constitutes another contribution made by this research.

\section{Country Image and COO Effect}

The initial studies on this issue had their beginning with the investigation carried out by Schooler (1965), who showed that the evaluations made by consumers of an hypothetic juice were different when comparing two products with the same specifications, but the information "made in" shown in only one of them. From then on, the number of published studies on this subject is surpasses 1000, with at least 400 of them being found in academic journals (Usunier, 2006).

Although 45 years old, the COO subject is still controversial in the literature. This is demonstrated by Roth and Diamantopoulos (2009), who divided the existing definitions of $\mathrm{COO}$ in three groups. In the first one, a more general concept is adopted, relating to the image of a country. The second group refers to such image influencing the product's one, which could be properly referred as a COO effect. Finally, the third group refers to $\mathrm{COO}$ as the image of products made in a certain country. For Roth and Diamantopoulos (2009), the inconsistency of such construct's definition results from a considerable conceptual confusion, when referring to its specification. They found that many studies refer to COO as "perception" (e.g. Allred et al. 2000; Han, 1989; Nebenzahl et al, 2003), terms related to "impression" or "association" (Ittersum et al., 2003), "stereotypes" (Hooley et al., 1988; Strutton et al., 1995; Verlegh and Steenkamp, 1999) or "schemas" (Askegaard and Ger, 1998; Ger 1991). According to Roth and Diamantopoulos (2009), few authors specify COO-related "beliefs" (Kotler et al., 1993; Martin and Eroglu, 1993), which represents a component of attitude (Zanna and Rempel, 1988).

The conceptual inconsistency mentioned above can be found in the three groups of definitions as classified by Roth and Diamantopoulos (2009). The first group includes definitions such as the one proposed by Papadopoulos (1993), for whom the term "country image" defines not only such image, but the thoughts derived from it in consumers' minds. Martin and Eroglu (1993, pp. 193) define country image as the "the total of all descriptive, inferential and informational beliefs one has about a particular country". Such definition is similar to the one found in Kotler et al. (1993), which refer to country image as the sum of beliefs and impressions people have regarding a certain place, representing the simplification of a large set of associations and pieces of information connected to this place. Kotler et al. (1993) also stress that country image is a mind product of an effort to process and choose essential information among a large quantity of data about a place. Other definitions from this group include Verlegh and Steenkamp (1999), who indicate that country image refers to the mental representations people develop regarding products, culture and national symbols of this country. For these authors, $\mathrm{COO}$ is not only a cognitive cue of a product's quality, but also refers to consumer's emotions, identity, pride and autobiographic memories.

The second group of definitions includes studies such as Nebenzahl et al. (2003), who define country image as the consumer's perception of the attributes of a product made in a certain country and his or emotions in relation to this country, resulting in the perception of the social convenience related to owning such products. For Papadopoulos and Heslop (2003), the image of a country is the place with which the buyer (or the seller) can associate a product. 
In the third group of definitions, Roth and Diamantopoulos (2009) list Nagashima (1970), for whom an image means a set of ideas with an emotional component, as well as concept-related connotations of the "made in" information, related in its turn to the reputation and stereotypes businessmen and consumers attribute to products of an specific country. Han (1989) considers country image as the difference of perceived quality between domestic and foreign products. Roth and Romeo (1992) indicate that such image is the total perception a consumer has regarding the products of a specific country, which is based in his or her previous perception of this country's production and its market's strong and weak points.

Although none of these definitions is incorrect, Roth and Diamantopoulos (2009) stress that most of them are not comprehensive enough to capture the domain of the construct "country image", which could be better measured via attitude. A closer examination of the subjacent concepts' nature in the definitions above (namely, perception, stereotypes, schemas and beliefs) indicates differences in the understanding of such construct. While attitude is defined as a learned disposition to behave in a consistently favorable or unfavorable way toward a determined object (Assael, 1995; Schiffman and Kanuk, 2007), an image is the total perception of an object, which is made by consumers via information processing along time (Assael, 1995).

This investigation aimed to assess image according to the most general, first group of definitions as classified by Roth and Diamantopoulos (2009), with fresh fruits being evaluated according to the attitude concept.

\section{Moderating Factors of the COO Effect}

Besides discussing COO's construct domain, it is also necessary to stress another aspect in order to better comprehend its effect. According to Bhaskaran and Sukumaran (2007), prior studies on consumers' beliefs and buying behavior related to a product's or service's COO presented two opposite conclusions. Some authors (Laroche et al., 2003; Agrawal and Kamakura, 1999; D'Astous and Ahmed, 1999) concluded that COO had a significant influence on choice, while others (Lim and Darley, 1997; Lim et al., 1994; Liefeld, 1993) did not observe so. For Bhaskaran and Sukumaran (2007), such apparent contradiction can be explained by contextual differences (such as product category or type, different COOs or buying occasions) and methodological ones, such as sample and buyer types.

Although decades of studies on the subject led to the seemingly unequivocal conclusion that a product's COO can influence consumer's evaluative judgments about this product, there is a constant debate on the magnitude of such effect and the cultural and ambient-related factors that can facilitate or inhibit trust in COO. Some of these $\mathrm{COO}$ effect's moderating factors are presented below.

According to a review by Giraldi and Ikeda (2009), the following consumers' characteristics can influence the COO effect: instruction and conservatism levels (Anderson and Cunningham, 1972), age (Shimp and Sharma, 1987) and gender (Johansson et al., 1985), fluency in the country's language (Balabanis et al., 2002), quantity of product-related cues (Chao and Rajendran, 1993), cognition need (Petty and Cacioppo, 1986), motivation (Maheswaran, 1994); (Gurhan-Canli and Maheswaran, 2000), involvement degree and familiarity with brand and 
culture (Verlegh et al., 1999). The COO effect can also vary according to country, used sample and assessed products (Martin and Eroglu, 1993).

Variables related to product type/category also have a role in the use of $\mathrm{COO}$ effect as criterion for alternative selection (Heslop and Papadopoulos, 1993; Papadopoulos, 1993). For example, $\mathrm{COO}$ information is generally more efficient for agriculture products than for manufactured ones, given the historical associations between production and $\mathrm{COO}$ (or region of origin; Agrawal and Kamakura, 1999). The consumer's involvement degree with agriculture products, in general, is smaller than for manufactured ones, leading to a higher COO effect in the evaluation of the first products.

Although the importance of the construct "country of origin" is known, there is no consensus in the literature regarding how to contextualize and operationalize the COO effect (Laroche et al., 2005). Up to date, no systematic analysis has been found, associated to a scale to measure such construct (Roth and Diamantopoulos, 2009). In the next topic, some of the strategies for measuring the $\mathrm{COO}$ effect are discussed.

\section{Measurement Strategies for the COO Construct}

The importance of $\mathrm{COO}$ can be measured via direct questioning, such as "when you buy a product, what is the importance of knowing where it was made?", or indirect one ("how do you assess the global quality of products made in Japan?”; D’Astous and Ahmed, 1999). However, direct assessments can be biased and imprecise (D'Astous and Ahmed, 1999). This can occur due to the difficulty, for the consumer, to assess the importance of COO in the context of buying decision. When asked about such importance, consumers may want to seem logical and rational and to base their purchases in intrinsic rather extrinsic cues of a product. Finally, the importance given to COO may depend on several moderating factors (Giraldi and Ikeda, 2009).

Due to such difficulties, many researchers adopt indirect assessment methods in order to investigate the $\mathrm{COO}$ effect, via experimental designs. The typical outline of such studies consists of a product's description according to a number of attributes (or cues) and the assessment of the impact of $\mathrm{COO}$ and other cues in the general evaluation of the product (Verlegh and Steenkamp, 1999). In these experiments, respondents assess products made in countries which image is considered as favorable and products made in countries with unfavorable images; thus, $\mathrm{COO}$ is manipulated as a variable. Other designs include presenting two identical products, with only their origins being changed, or asking consumers to assess products from a series of different countries. In these cases, product descriptions are offered to the consumers, mainly verbally.

Little is known about the reasons (or cues) related to good or bad evaluations (Verlegh and Steenkamp, 1999). Examples of experimental studies are Schooler (1965), Chao and Rajendran (1993) and Gurhan-Canli and Maheswaran (2000). In order to overcome this problem of experiments not providing explanations for the obtained country image, this study proposes an innovative way to measure the $\mathrm{COO}$ effect; by means of the structural equation modeling approach. Such an approach has not been seen before in past researches, constituting a contribution by this research, and it makes possible to evaluate the influence of country image on the attitude towards products, pointing out the dimensions where the country has not a good performance. 
Moreover, for Nebenzahl et al. (2003), most of the studies on COO focus almost exclusively on product evaluation, using the scale developed by Nagashima (1970), which describes only physical characteristics of the product or the country. It was noticed a gap in such scales, for they do not provide a measure of emotions and social influences in consumers' choices. In order to contribute for complementing the existing scales and the other ways to measure the $\mathrm{COO}$ effect, researchers made changes in the strategies used to measure such construct. An example of an effort to identify emotive dimensions is the study by Hooley et al. (1988), who used items such as "what do you think of people who buy (products, categories) from each of the following countries?". Another example is Nebenzahl et al. (2003), who used a 27-item personification scale, such as: "Someone who buys products made in (country) is...". Other statements require assessment according to an agreement scale, with questions such as "Products made in (country) are high-quality products". The scale consists of two parts, with the first one containing items directly related to the products and the second one, items related to people who consume such products. The scale captures not only evaluative dimensions of the products being analyzed, but also social and emotional ones.

The literature review shows an evolution in the number of dimensions assessed by researchers along their studies. According to Roth and Diamantopoulos (2009), the biggest concern should not be about developing a new scale for measuring the COO construct, but, considering the high number of such scales, efforts should be made on how to assess them and how to approach the construct in future studies.

\section{Brazilian Agribusiness and Fruit Culture}

According to Brazilian Ministry of Development, Industry and Foreign Trade, Brazilian exportations reached a total of US\$ 11.305 billion in January, 2010 (average daily amount of US\$ 565.3 million). Such daily amount was $21.3 \%$ higher than the one registered one year before (US\$ 465.8 million). Importations reached US\$ 11.471 in January, 2010, with an average daily amount of US\$ 573.6 million (16.8\% higher than one year before, US\$ 491 million). The main importers of agricultural products, considering agribusiness worldwide are, in decrescent order, the USA, Germany, Japan, UK, France, Italy and the Netherlands. When considering the main destinations of Brazilian agribusiness exportations, the Netherlands stand out as the second place (with China as the first one), being so, a very important purchaser of Brazilian agribusiness (MDICE, 2008).

Fruit culture is being pointed out as promising activity for the development of Brazilian agribusiness, with favorable conditions for fruit culture's growing. Such conditions include the existence of both national and state programs, an increase in fruit consumption, exportation possibilities, incentives for employment and income generation for familiar farming and feeding complementation, among others. Besides this, fruit culture is one of the most growing activities in Brazilian agriculture, due to the country's climatic diversity, allowing for the production of several types of both tropical and temperate fruits (MAPA, 2005). To Blisard et al. (2002), from 2000 to 2020, the per capita outlay on fruits and vegetables will increase more than any other product category worldwide. Data from the FAO (2007) indicate that the global production of fruits had an increase of $26 \%$ since last decade (Teixeira, 2008).

According to the Brazilian Fruit Institute (IBRAF, 2009), Brazil is the world's third biggest fruit producer, behind only China and India. Its large domestic consumption, though, which 
absorbs most of the harvest, leads Brazil to the $15^{\text {th }}$ position in the ranking of the biggest exporters. The European Union is the biggest buyer of Brazilian fruits, absorbing $76 \%$ of the total exported production. The Netherlands stands out, as this country acts as a re-exporter in the EU, redistributing fruits to other nations, mainly Germany. After the Netherlands, the main Brazilian fruits' exporters are the UK, USA, Spain, Germany and Portugal (IBRAF, 2009). Besides the EU and the USA, Brazil exports its fruits to countries in the Middle East (such as Saudi Arabia, United Arab Emirates and Kuwait), Asia (mainly Bangladesh) and Africa (such as Libya, Sudan, among others), in a total of 79 countries worldwide (IBRAF, 2009).

According to Favaret Filho et al. (1999), the mainly commercialized and consumed fruits worldwide are orange, apple, grapes, banana, peach, pear and pineapple. From these, banana, pear and pineapple are the most consumed ones (in natura above all), while orange and apple are consumed in juice form. Considering this, few studies were found in the literature addressing the image of Brazilian fresh fruits abroad. Teixeira (2008) reports that Costa Rica is Brazil's direct competitor in the segment of tropical fruits, while South Africa competes with Chile in the segment of apples and grapes. Banana and first-impact attributes such appearance, taste, nutrition and brand were associated to Brazil, suggesting a positioning of attractiveness. Teixeira (2008) observes that other important attributes, such as price and security, are related to Costa Rica and South Africa, respectively. Older consumers attribute value to social and environmental responsibility, showing that such attributes could be invested by Brazilian fruit culture in order to enhance the reliability on this product's offer and participation in the international market.

Another study was carried out by Bacha and Vianna (2007), who aimed to analyze the importance of "Brazil brand" in the internationalization process of the country's fresh fruits. These authors observed most of respondents (exportation companies in Brazil's south region) consider the brand's logo as beautiful, which could have a positive interaction with the exported fruits' brands, leading to an enhancement of their identity and constituting a marketing strategy in order to attract foreign markets.

\section{Methodology}

This research population was defined as Dutch students from the School of Economics Haarlem, Netherlands. Such target population was defined so due to easy access to respondents, as the present research was supported by professors from that college, who applied the questionnaire used by this research. Young undergraduate students are a segment of interest for companies, once they consist of potential consumers of products exported to the Netherlands. This country was chosen for being an important gateway for Brazilian products in Europe, since the harbor of Rotterdam is used as an outpost for such products. The Netherlands occupied, in 2009, the fourth place in the ranking of biggest buyers of Brazilian products (Federal Revenue of Brazil, 2010).

Some comments must be made on the type of size of the sample used for the empirical study. As nothing is known on the proportion of Dutch students of the School of Economics Haarlem with a positive attitude toward Brazilian products (one of variables herein investigated), the criterion adopted for the sample size was the value of $\mathrm{p}=\mathrm{q}=50 \%$. By doing so, a maximum number of elements that constitute the sample is reached (McDaniel and Gates, 1996). The remaining calculation indicates a sample size of $n=400$ (from a sampling frame of about 1900 
students), considering a margin of error of $5 \%$ and a confidence level of $95 \%$. Considering the adjustment rule for finite populations, a sample size of $n=331$ was obtained. The sampling frame of the present student was a list of students' emails, which allowed for random selecting the elements.

Data collection was performed via electronic, self-administered questionnaires. Students were invited by professors to voluntarily participate in the research, without any payment. A great number of variables was assessed, as the questionnaire also included the assessment of other Brazilian products, not covered in this paper. The access to the sample was difficult, due to its localization in a different country than the authors'. The questionnaire was also made available in an internet page, to which respondents were directed through a link sent in the invitation email.

In order to assess the image these foreign consumers have regarding Brazil, the authors used all fifteen questions related to the five dimensions of country image, as identified by Ayrosa (2002). These dimensions were beliefs related to the country's products and services, emotive response toward the country, beliefs related to arts, communication and distribution, and importance in the global community. Such scale was chosen for its dimensional structure and solid internal consistency, besides being more complete than the one used by Pisharodi and Parameswaran (1992), in which it was based on. In order to assess attitude toward Brazilian fresh fruits, a three-component model was adopted, according to which attitudes comprehend three major components (cognitive, affective and conative). According to Schiffman and Kanuk (2007), such components must be measured in any study that assess attitude. In the present study, the authors adopted the scales indicated by Assael (1995) and McDaniel and Gates (1996) for measuring all three components of attitude (see Table 1).

The variables stated in the negative valence were inverted for the analyzes. The questions about Brazil's image and attitude toward Brazilian fresh fruits were answered using a 5-point scale, in which number 1 corresponded to "I totally disagree" and 5 to "I totally agree".

All questions regarding Brazil's image were initially submitted to exploratory factor analysis, in order to identify subjacent dimensions to be inserted in the model. Later, the resultant dimensions and all questions about attitude were analyzed in a confirmatory approach. The analytical framework herein adopted for estimating the parameters of the proposed model was the partial least squares regression (PLS), using the software SmartPLS (v. 2.0.M3). This is a modeling tool of structural equations, which uses a component-based approach for performing the estimation.

For Sirohi et al. (1998), PLS is a strong technique for analyzing structural equation models of latent variables with multiple indicators. Chin (1998) explains that PLS employs an estimation procedure based on minimum squares, which does not apply pressure on measurement scales, distribution suppositions or sample size. Such effect is observed with other tools based on structural equations that are based in the covariance (like LISREL and EQS), as these tools use a maximum likelihood function for obtaining an estimation of the parameters. 
Table 1. Attitude toward Brazilian fresh fruits: questions and labels

\begin{tabular}{|c|c|c|}
\hline $\begin{array}{l}\text { Attitude } \\
\text { Components }\end{array}$ & Questions & $\begin{array}{l}\text { Variable } \\
\text { labels }\end{array}$ \\
\hline \multirow{4}{*}{ Cognitive } & Brazilian fresh fruits are reputable & Fruicog1 \\
\hline & Brazilian fresh fruits are expensive & Fruicog2 \\
\hline & Brazilian fresh fruits are prestigious & Fruicog3 \\
\hline & Brazilian fresh fruits are low quality fruits & Fruicog4 \\
\hline \multirow{4}{*}{ Affective } & I dislike Brazilian fresh fruits & Fruiafe1 \\
\hline & $\begin{array}{l}\text { I think Brazilian fresh fruits are better than the ones from } \\
\text { other countries }\end{array}$ & Fruiafe2 \\
\hline & I admire Brazilian fresh fruits & Fruiafe3 \\
\hline & I am sympathetic for Brazilian fresh fruits & Fruiafe4 \\
\hline \multirow{3}{*}{ Conative } & I could buy Brazilian fresh fruits & Fruicon1 \\
\hline & I would not recommend Brazilian fresh fruits to a friend & Fruicon2 \\
\hline & $\begin{array}{l}\text { I prefer Brazilian fresh fruits than the ones from other } \\
\text { countries }\end{array}$ & Fruicon3 \\
\hline
\end{tabular}

In the estimated model, the strength of the relation between Brazil's image and attitude toward Brazilian fresh fruits was analyzed using the determination coefficient $\left(\mathrm{R}^{2}\right)$ of the regression analysis, with such coefficient being and indirect measurement of the COO effect. The $\mathrm{R}^{2}$ was considered as a measure of the magnitude of such effect in the present study. In order to check for the valence of the $\mathrm{COO}$ effect, that is, whether the influence of country image in the attitudes toward the products made in such country is positive or negative, the authors used the model's regression coefficient $(\beta)$.

\section{Results}

Although efforts have been made in order to substitute participants who did not take part of the study, 229 responses were obtained, and so, less than the 331 participants initially planned (response rate of $12.05 \%$; total $\mathrm{N}=1900$ ). The final sample totalized 116 participants, who completely filled in the questionnaire. Due to this fact, it was necessary to adjust the data's margin of error for the obtained sample. Considering the adjustment rule for finite populations, the sample was analyzed with a $9 \%$ margin of error and a $95 \%$ confidence level.

The sample was composed in its majority of very young (99.1\% not older than 18), mostly male (54.3\%) students, with some knowledge about Brazil. As it can be seen on Table 2, only $11.2 \%$ declared knowing nothing about the country. Table 3 shows the degree of knowledge about the product studied (fresh fruits). It can be observed that $71.6 \%$ of the respondents have already bought the product, either a few or many times. 
The obtained data was considered adequate for factor analysis, according to the results of Bartlett's sphericity test (which showed significant correlations) and the Kaiser-Meyer-Olkin Test (KMO), which displayed a value of 0.775 . The procedures adopted for the exploratory factor analysis were the analysis of principal components for factor extraction, considering eigenvalues higher than 1 as the choice criterion for the number of factors. Also, the authors used a Varimax (orthogonal) rotation and Cronbach's alpha for assessing the internal consistency. An orthogonal rotation method was chosen due to the fact that its resultant factors should not be highly correlated, so that multicolinearity was avoided when performing subsequent regression analyzes (Hair, Jr. et al. 1995).

Table 2. Respondents' level of knowledge about Brazil

\begin{tabular}{lllll}
\hline & Frequency & $\%$ & Valid \% & Accumulated \% \\
\hline I have already been to Brazil & 17 & 14.7 & 14.7 & 14.7 \\
I have already read about Brazil & 42 & 36.2 & 36.2 & 50.9 \\
I have heard about Brazil & 44 & 37.9 & 37.9 & 88.8 \\
I know nothing about Brazil & 13 & 11.2 & 11.2 & 100.0 \\
Total & 116 & 100.0 & 100.0 & \\
\hline
\end{tabular}

Table 3. Buying profiles of Brazilian fresh fruits

\begin{tabular}{lllll}
\hline & Frequency & $\%$ & Valid \% & Accumulated \% \\
\hline I have never bought the product & 12 & 10.3 & 10.3 & 10.3 \\
I have bought the product a few times & 43 & 37.1 & 37.1 & 47.4 \\
I have bought the product many times & 40 & 34.5 & 34.5 & 81.9 \\
I do not know the origin of the product I buy & 21 & 18.1 & 18.1 & 100.0 \\
Total & 116 & 100.0 & 100.0 & \\
\hline
\end{tabular}

Five factors with eigenvalues higher than 1 were obtained, corresponding to the theoretical factors predicted by Ayrosa (2002). These factors explain $67.519 \%$ of the total variance of the elements. Table 4 shows the values of Cronbach's alpha. All factors presented alpha coefficients higher than 0.70 , being thus reliable. Factor 1 (32.5\% of total variance) represents the evaluations of Brazilian products, being called Product Evaluation.

Factor 2 (12.03\% of total variance) represents the evaluations of Brazilian arts, being called Art Evaluation. In its turn, Factor 3 (8.44\% of total variance) is related to evaluations of the respect and importance of Brazil in world economy and politics, being called Brazil's respect and importance. Factor 4 (7.98\% of total variance) aggregated items related to evaluations of 
communication and distribution activities, being called Communication and distribution evaluation. Finally, Factor 5 (6.56\% of total variance) represents affection toward Brazil, having being called so.

The resulting dimensions from factor analysis were used as independent variables in the structural model estimated with PLS. As suggested by Chin (1998), the psychometric properties of the model were assessed in order to exam internal consistency's reliability, convergent and discriminant validity. Based in the results of the exploratory factor analysis, the analyzed relations are shown in Figure 1 (measurement and structural models; all indicators are reflexive). 
Table 4. Rotated component matrix of Brazil's image

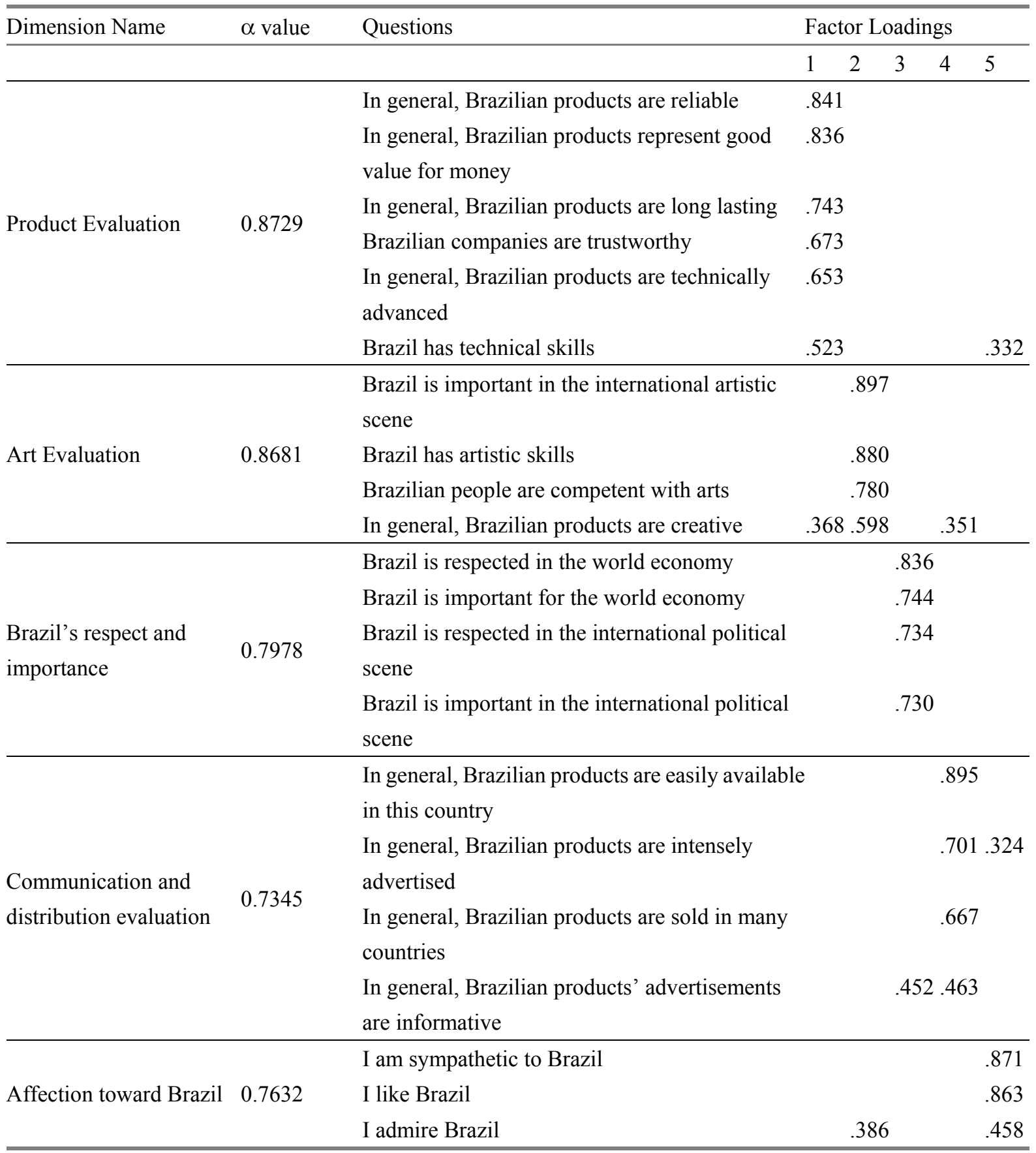

According to the recommendations made by Hulland (1999), indicators with factor loads too below 0.50 were not retained. Some items measuring the attitude towards Brazilian fresh fruits were not kept in the final model (Fruicog3, Fruicog4, Fruiafe1, Fruiafe2, Fruicon1 and Fruicon4 were disregarded). Brazil's image is a second-order, latent variable (indicators were omitted and previously calculated in the exploratory factor analysis). 


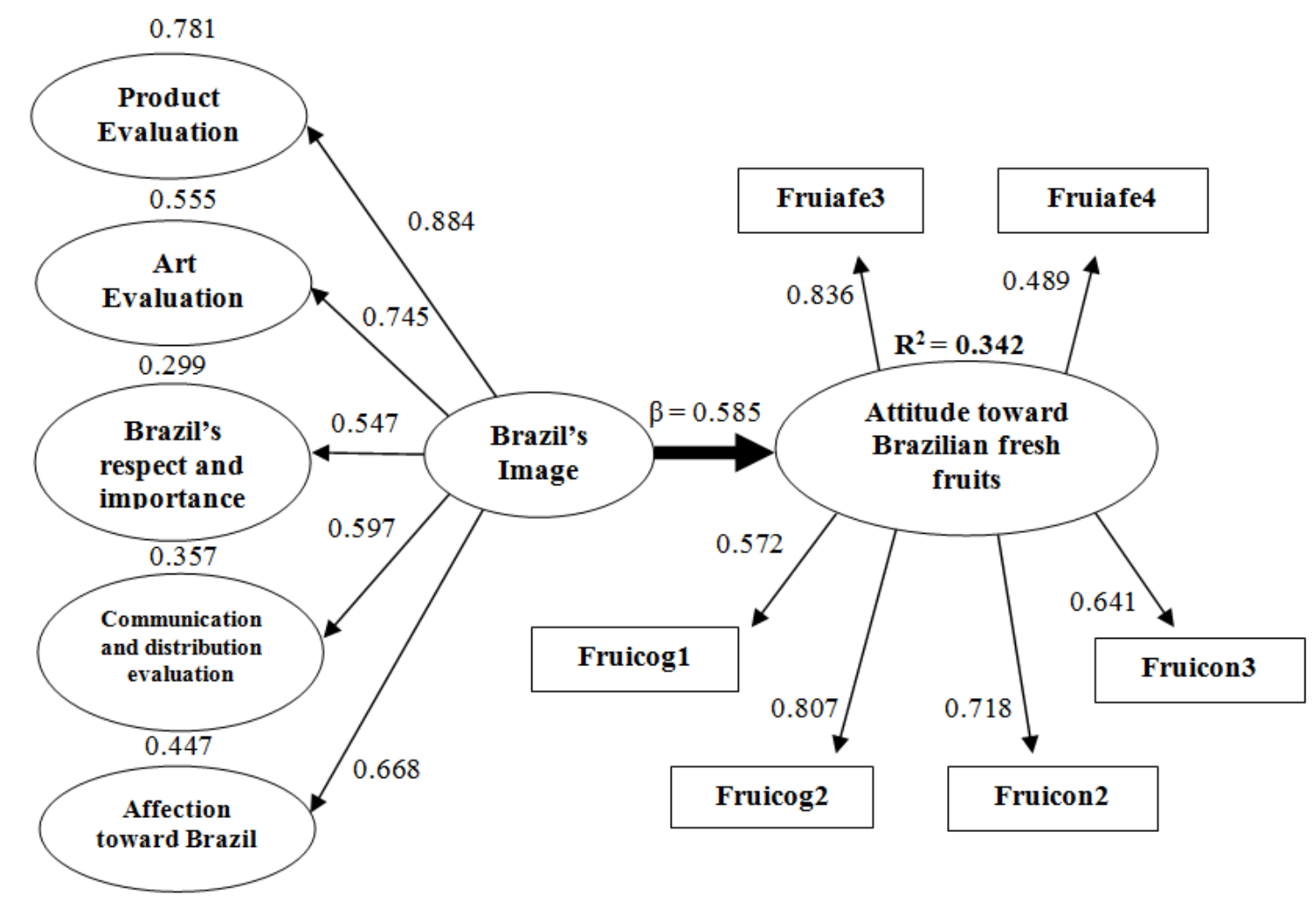

Figure 1. Structural and measurement models of the relation between Brazil's image and attitude toward Brazilian fresh fruits

The estimation algorithm was executed and the results (coefficients, composed reliability and average variance extracted) are presented in Table 5. The average variance extracted (AVE) measures the quantity of variance captured by the construct in relation to the quantity of variance related to measurement error. A composed reliability index was used instead of Cronbach's alpha. Although similar, the first index is preferred in structural equation modeling, for it estimates internal consistency based in real measurement loads. For first-order factors, AVE values and the composed reliability were directly obtained from the outputs of the SmartPLS software. For the second-order factor (Brazil's image), AVE values were calculated according to the recommendations of Hair, Jr. et al. (1995). The model's coefficients are highly significant (Sig. $<0,001)$, with their estimations having been calculated via bootstrap $(\mathrm{n}=116$, 300 repetitions).

Table 5 also shows that all values for the composed reliability are above the 0.70 cut-off for the first-order variables and close to 0.70 for the second-order variable, indicating the results are reliable. Establishing convergent validity requires an AVE value below 0.50, which evidences that due-to-error variance is smaller than the one captured by the construct (Fornell and Larcker, 1981). Table 5 shows that the factors "Attitude toward Brazilian fresh fruits" and "Brazil's image" have values close to 0.50. Thus, all AVEs show acceptable convergent validity. 
Discriminant validity was assessed according to the criteria suggested by Fornell and Larcker (1981) for models with reflexive indicators. The square root of the AVE (Table 5) is higher than all its correspondent correlations (see Table 6 for first-order variables). The proposed model also shows discriminant validity. Each latent construct responds for more of the variance with its own indicators than they share it with another construct.

Table 5. Specifications of the structural model

\begin{tabular}{lllll}
\hline & AVE & VAVE & $\begin{array}{l}\text { Composed } \\
\text { Reliability }\end{array}$ & $\mathbf{R}^{2}$ \\
\hline Attitude toward Brazilian fresh fruits & 0.473987 & 0.6885 & 0.839545 & 0.342017 \\
Brazil's image & 0.487665 & 0.6983 & 0.698878 & - \\
Affection toward Brazil & 0.686409 & 0.8285 & 0.867611 & 0.446514 \\
Art Evaluation & 0.715737 & 0.8460 & 0.909543 & 0.554692 \\
Communication and distribution Evaluation & 0.545451 & 0.7385 & 0.826792 & 0.356724 \\
Product Evaluation & 0.615209 & 0.7844 & 0.904882 & 0.781092 \\
Brazil's respect and importance & 0.625230 & 0.7907 & 0.869525 & 0.299064 \\
\hline
\end{tabular}

Table 6. Correlations for first-order latent variables

\begin{tabular}{lllllll}
\hline & $\# \mathbf{1}$ & $\mathbf{\# 2}$ & $\mathbf{\# 3}$ & $\mathbf{4 4}$ & $\mathbf{\# 5}$ & \#6 \\
\hline \#1. Attitude toward Brazilian fresh fruits & 1.00 & & & & & \\
\#2. Affection toward Brazil & 0.633831 & 1.00 & & & & \\
\#3. Art Evaluation & 0.507257 & 0.477205 & 1.00 & & & \\
\#4. Communication and distribution & 0.239672 & 0.242944 & 0.281655 & 1.00 & & \\
Evaluation & & & & & & \\
\#5. Product Evaluation & 0.464506 & 0.489401 & 0.517614 & 0.429613 & 1.00 & \\
\#6. Brazil's respect and importance & 0.147876 & 0.154063 & 0.205669 & 0.380008 & 0.403488 & 1.00 \\
\hline
\end{tabular}

Roth and Diamantopoulos (2009) report a general lack of validity and reliability assessments in studies about COO, which is somehow overcome in the present study. This research problem was: "Which is the impact of Brazil's image in the evaluation of Brazilian fresh fruits?" In order to answer this question, both determination $\left(R^{2}\right)$ and regression coefficient $(\beta)$ values must be analyzed. For the present model, $\mathrm{R}^{2}=0.342$. Hence, the variables have a moderate relation, with Brazil's image explaining $34.2 \%$ of the variation observed in the attitudes toward Brazilian fresh fruits. 
In order to check whether the influence of Brazil's image for the dependent variable "Attitude toward Brazilian fresh fruits" is positive or negative, the model's regression coefficient was analyzed. In Figure 1, it can be seen that $\beta=0.585$ (Sig. $<0,001$ ). Thus, Brazil's image has a positive effect in foreign consumers' evaluation of Brazilian fresh fruits, as herein measured based in the three-component model of attitude.

\section{Final remarks}

This study aimed to investigate the influence of the image a group of foreign consumers have about Brazil over the attitudes toward fresh fruits, via an empirical study with Dutch undergraduate students. It was verified, both in the literature review and empirically, that country image is not a unique, one-dimensional construct. When analyzing the image of a certain country, all dimensions must be considered, so that its positive or negative causes can be understood. The resulting dimensions of Brazil's image herein found were Product Evaluation, Brazil's Respect and Importance, Art Evaluation, Affection toward Brazil and Communication and Distribution Evaluation. These dimensions were consistent with the ones obtained by Ayrosa (2002), whose scales served as a basis for this study.

It can be concluded that the $\mathrm{COO}$ effect exists for Brazilian fresh fruits and it is positive, meaning that the image participants have about Brazil positively affects their attitudes toward such product. These results can help Brazilian companies in this area who must deal with COO-related questions in their international marketing activities. The results can also offer more elements for the discussion about using "Brazil brand" in the exportation of products made in this country, as the present study verified whether Brazil's image favors or impairs the product herein investigated.

It is also highlighted that this study used an innovative way to measure the COO effect (structural equation modeling approach). Such an approach has not been seen before in past researches, constituting a contribution of this research, and it makes possible to point out the dimensions where the country has not a good performance.

Some limitations must be stressed. The first one is the defined target-population, which does not cover other important markets with which Brazil has commercial relations, like other European countries, the USA, China, or even different segments of Dutch consumers. Other limitations refer to the field study adopted. Firstly, the online questionnaire was regarded as too long for some respondents, which could explain the number of incompletely filled in ones. Such risk was taken in consideration when choosing the data collecting form, though. As there would be no other access to respondents due to geographic distance, the electronic questionnaire was maintained.

The results obtained (as well as its limitations) suggest issues to be approached by future studies. They include increasing the number of products and countries to be analyzed, so that the existence of and valence of the $\mathrm{COO}$ effect over Brazilian products can be confirmed. Other studies should address the role of moderating factors in the relation between country image and product evaluation. 


\section{References}

Agrawal, J., \& Kamakura, W. A. (1999). Country of origin: a competitive advantage. International Journal of Research in Marketing, 16(4), 255-267. http://dx.doi.org/10.1016/S0167-8116(99)00017-8

Allred A. et al. (2000). Measuring images of developing countries: a scale development study. Journal of Euromarketing, 8(3), 29-49. http://dx.doi.org/10.1300/J037v08n03 02

Anderson, W. T., \& Cunningham, W. H. (1972). Gauging foreign product promotion. Journal of Advertising Research, 12(1), 29-34.

Askegaard, S., \& Ger, G. (1998). Product-country images: toward a contextualized approach. European advances in consumer research, 3, 50-58.

Assael, H. (1995). Consumer behaviour and marketing action. Cincinnati: South-Western College Publishing.

Ayrosa, E. A. T. (1998). Imagem de país: uma escala para avaliar atitudes relativas a países. Proceeding of the 22 Encontro Nacional da Associação Nacional de Pós-Graduação e Pesquisa em Administração, Foz do Iguaçu, PR, Brasil, 22.

Ayrosa, E. A. T. (2000). Some notes on the development of research on country-of-origin effects. Arché Interdisciplinar, Rio de Janeiro, IX, 26.

Ayrosa, E. A. T. (2002). Validation of a scale to measure country image in Brazil. Proceedings of BALAS (The Business Association of Latin American Studies Annual Conference), Brazil, 2002, Anais... São Paulo, CD-ROM.

Bacha, M. L., \& Viana, N. (2007). Marca Brasil como instrumento para internacionalização de frutas frescas brasileiras. Proceedings of the $4^{\circ}$ Congresso do Instituto Franco-Brasileiro de Administração de Empresas, Porto Alegre, Brazil, 2007. Retrieved from: http://www.ifbae.com.br/congresso4/pdf/B204.pdf

Balabanis, G. et al. (1999). Country of origin images around the world: can value priorities predict them? Proceedings of the $28^{\text {th }}$ EMAC Conference, Berlin, 1999. CD-ROM.

Balabanis, G. et al. (2002). The human value's lenses of country of origin images. International Marketing Review, 19(6), 582-610. http://dx.doi.org/10.1108/02651330210451935

Bhaskaran, S., \& Sukumaran, N. (2007). Contextual and methodological issues in COO studies. Marketing Intelligence \& Planning, 25(1), 66-81. http://dx.doi.org/10.1108/02634500710722407

Blisard, N. et al. (2002). America's changing appetite: food consumption and spending to 2020. Food Review, 25(1), 2-9. 
Chao, P., \& Rajendran, K. N. (1993). Consumer profiles and perceptions: country-of-origin effects. International Marketing Review, 10(2), 22-39. http://dx.doi.org/10.1108/02651339310032534

Chin, W. W. (1998). The partial least squares approach to structural equation modeling. In: Marcoulides, G. A. (ed.), Modern Methods for Business Research, Mahway: Lawrence Erlbaum, 295-336.

D'Astous, A., \& Ahmed, S. A. (1999). The importance of country images in the formation of consumer product perceptions. International Marketing Review, 16(2), 108-120. http://dx.doi.org/10.1108/02651339910267772

FAO - Food and Agriculture Organization. (2009). Retrieved March 03, from: www.fao.org

Favaret Filho, P. et al. (1999). Fruticultura brasileira: a busca de um modelo exportador. Rio de Janeiro: BNDES press.

Federal Revenue of Brazil. (2010). Retrieved May 14, from: http://www.receita.fazenda.gov.br/

Fornell, C., \& Larcker, D. F. (1981). Evaluating structural equation models with unobservable variables and measurement error. Journal of Marketing Research, 28(1), 39-50. http://dx.doi.org/10.2307/3151312

Ger, G. (1991). Country image: perceptions, attitudes, associations and their relationships to context. Proceedings of the $3^{\text {rd }}$ International Conference on Marketing and Development, New Delhi, India, 390-398.

Giraldi, J. M. E., \& Ikeda, Ana Akemi. (2009). Personal values and the 'country-of-origin effect': the moderating role of consumers' demographics. International Journal of Consumer Studies, 33(3), 309-315. http://dx.doi.org/10.1111/j.1470-6431.2009.00765.x

Gurhan-Canli, Z., \& Maheswaran, D. (2000). Determinants of country-of-origin evaluations. Journal of Consumer Research, 27(1), 96-108. http://dx.doi.org/10.1086/314311

Hair, Jr., J. F. et al (1995). Multivariate data analysis. Upper Saddle River: Prentice Hall.

Han, C. M. (1989). country image: halo or summary construct? Journal of Marketing Research, 26(2), 226-229. http://dx.doi.org/10.2307/3172608

Heslop, L. A., \& Papadopoulos, N. (1993). But who knows where or when: reflections on the images of countries and their products. In: Papadopoulos, N. \& Heslop, L. A. Product-country images: impact and role in international marketing, London: Haworth Press, 39-76.

Hooley et al. (1988). A method for modelling consumer perceptions of country of origin. International Marketing Review, 5(3), 67-76. http://dx.doi.org/10.1108/eb008359

Hulland, J. (1999). Use of partial least squares (PLS) in strategic management research: a review of four recent studies. Strategic Management Journal, 20(2), 195-204. doi: 10.1002/(SICI)1097-0266(199902)20:2<195::AID-SMJ13>3.0.CO;2-7 
IBRAF (Brazilian Fruit Institute, 2009). Retrieved January 03, 2010, from: http://www.ibraf.org.br

Ittersum, K. V. et al. (2003). The influence of the image of a product's region of origin on product evaluation. Journal of Business Research, 56(3), 215-226. http://dx.doi.org/10.1016/S0148-2963(01)00223-5

Jaffe, E. D., \& Nebenzahl, I. D. (2001). National image and competitive advantage: the theory and practice of country-of-origin effect. Copenhagen: Copenhagen Business School Press.

Johansson et al. (1985). Assessing the impact of country of origin on product evaluation: a new methodological perspective. Journal of Marketing Research, 22(4), 388-396. http://dx.doi.org/10.2307/3151584

Kotler, P. et al. (1993). Marketing places: attracting investment, industry, and tourism to cities, states, and nations. NewYork: Free Press.

Laroche et al. (2003). Effects of subcultural differences on country and product evaluations. Journal of Consumer Behaviour, 2(3), 232-247. http://dx.doi.org/10.1002/cb.104

Laroche et al. (2005). The influence of country image structure on consumer evaluations of foreign products. International Marketing Review, 22(1), 96-115. http://dx.doi.org/10.1108/02651330510581190

Liefeld, J. P. (1993). Consumer use of country-of-origin information in product evaluations: evidence from experiments. In: Papadopoulos, N. \& Heslop, L. A. (Eds). Product-Country Image: Impact and Role in International Marketing. New York: International Business Press, 117-156.

Lim, J. S., \& Darley, W. K. (1997). An assessment of demand artefacts in country-of-origin studies using three alternatives, International Marketing Review, 14 (4), 201-217. http://dx.doi.org/10.1108/02651339710173417

Lim, J. S. et al. (1994). An assessment of country of origin effects under alternative presentation formats. Journal of the Academy of Marketing Science, 22(3), 274-282. http://dx.doi.org/10.1177/0092070394223008

Maheswaran, D. (1994). Country-of-origin as a stereotype: effects of consumer expertise and attribute strength on product evaluations. Journal of Consumer Research, 21(2), 354-365. http://dx.doi.org/10.1086/209403

MAPA (Brazilian Ministry on Agriculture, Livestock and Supplying - Secretary of International Relations of the Agribusiness) (2010). Retrieved January 24, 2010, from: http://www.agricultura.gov.br/

Martin, I. M., \& Eroglu, S. (1993). Measuring a multi-dimensional construct: country image. Journal of Business Research, 28(3), 191-210. http://dx.doi.org/10.1016/0148-2963(93)90047-S 
McDaniel, C., \& Gates, R. (1996). Contemporary marketing research. Saint Paul: West Publishing Company.

MDICE (Brazilian Ministry of Development, Industry and Foreign Trade) (2008). Retrieved March 8, 2009, from: http://www.mdic.gov.br/sitio/

Nagashima, A. A. (1970). Comparison of Japanese and U.S. attitudes toward foreign products. Journal of Marketing, 34(1), 68-74. http://dx.doi.org/10.2307/1250298

Nebenzahl, I. D. et al. (2003). Personifying country of origin research. Management International Review, 43(4), 383-406.

Papadopoulos, N., \& Heslop, L. (2003). Country Equity and product-country images: state of the art in research and implications. In: Subhash C. Jain (Ed.), Handbook of research in international marketing. Northampton, MA: Edward Elgar Press, 402-433.

Papadopoulos, N. (1993). What product and country images are and are not. In: Papadopoulos, N. \& Heslop, L. (Eds.), Product-country images: impact and role in international marketing. Binghamton: International Business Press, 3-38.

Petty, R. E., \& Cacioppo, J. T. (1986). The elaboration likelihood model of persuasion. New York: Springer-Verlag.

Pisharodi, R. M., \& Parameswaran, R. (1992). Confirmatory factor analysis of a country-oforigin scale: initial results. Advances in Consumer Research, 19, 706-714.

Roth, K. P., \& Diamantopoulos, A. (2009). Advancing the country image construct. Journal of Business Research, 62(7), 726-740. http://dx.doi.org/10.1016/j.jbusres.2008.12.012

Roth, M. S., \& Romeo, J. B. (1992). Matching product category and country image perceptions: a framework for managing country-of-origin effects. Journal of International Business Studies, 23, 477-497. http://dx.doi.org/10.1057/palgrave.jibs.8490276

Schiffman, L. G., \& Kanuk, L. L. (2007). Consumer behavior. Upper Saddle River, N.J.: Prentice Hall.

Schooler, R. (1965). Product bias in the central american common market. Journal of Marketing Research, 2(4), 394-397. http://dx.doi.org/10.2307/3149486

Shimp, T. A., \& Sharma, S. (1987). Consumer ethnocentrism: construction and validation of the CETSCALE. Journal of Marketing Research, 24(3), 280-90. http://dx.doi.org/10.2307/3151638

Sirohi, N. et al. (1998). A model of consumer perceptions and store loyalty intentions for a supermarket retailer. Journal of Retailing, 74(2), 223-45. http://dx.doi.org/10.1016/S0022-4359(99)80094-3

Strutton, D., True, S., \& Rody, R. C. (1995). Russian consumer perceptions of foreign and domestic consumer goods: An analysis of country-of-origin stereotypes with implications for promotions and positioning. Journal of Marketing Theory Practice, 3(3), 76-97. 


\section{Macrothink}

Journal of Management Research

ISSN 1941-899X 2012, Vol. 4, No. 4

Teixeira, L. (2008). Posicionamento de frutas brasileiras no exterior do ponto de vista do consumidor: um estudo comparativo da imagem de frutas estrangeiras no mercado holandês. Dissertation (Master Degree in Business), FEARP/USP, Brazil.

Usunier, J. C. (2006). Relevance in business research: the case of country-of-origin research in marketing. European Management Review, 3(1), 60-73. http://dx.doi.org/10.1057/palgrave.emr.1500049

Verlegh, P. W. J. et al. (1999). Country stereotypes: cognition, affect and product judgment. Proceedings of the 28th EMAC Conference, Berlim. CD-ROM.

Verlegh, P. W. J., \& Steenkamp, J. B. E. M. (1999). A review and meta-analysis of country-of-origin research. Journal of Economic Psychology, 20(5), 521-546. http://dx.doi.org/10.1016/S0167-4870(99)00023-9

Zanna, M. P., \& Rempel, J. R. (1988). Attitudes: a new look at an old concept. In: Bar-Tal D. and Kruglanski A. (Eds.) The social psychology of knowledge. New York: Cambridge University Press, 315-334. 